\title{
Уровень заболеваемости
} цереброваскулярными болезнями, летальности и смертности в Московской области в 2014 г.

Гуров А.Н. • Катунцева Н.А.

Гуров Андрей Николаевич - д-р мед. наук, профессор, начальник научноорганизационного отдела'

$\bowtie 129110$, г. Москва, ул. Щепкина, 61/2-3, Российская Федерация.

Тел.: +7 (495) 6844587.

E-mail:kafedraoz@mail.ru

Катунцева Нина Александровна канд. мед. наук, доцент, заведующая отделением проблем здоровья населения и региональных программ здравоохранения'
1 ГБУЗ МО «Московский областной научно-исследовательский клинический институт им. М.Ф. Владимирского»; 129110, г. Москва, ул. Щепкина, 61/2, Российская Федерация
Актуальность. Цереброваскулярные болезни вносят значительный вклад в смертность населения. В Московской области от цереброваскулярных болезней ежегодно умирают более 14 тыс. человек, из них около 50\% - в условиях стационара.

Цель - информационное обеспечение программ, направленных на снижение заболеваемости, летальности и смертности населения от цереброваскулярных болезней, в том числе инсультов, повышение качества медицинской помощи и в конечном счете сохранение здоровья и качества жизни пациентов.

Материал и методы. Рассчитаны показатели, характеризующие смертность, больничную летальность, общую (по обращаемости) и госпитальную заболеваемость цереброваскулярными болезнями в Московской области за 2014 г. Источником информации послужили отчетные формы Федерального статистического наблюдения № 12 и № 14, а также материалы службы государственной статистики по Московской области, отражающие смертность населения. Прослежены динамические изменения показателей на протяжении последних 5 лет.

Результаты. Ведущей причиной общей заболеваемости (по обращаемости) взрослого населения Московской области является группа заболеваний «другие цереброваскулярные болезни» (в соответствии с Международной классификацией болезней 10-го пересмотра), включающая церебральный атеросклероз и другую хроническую патологию, - 35,3 на 1000 населения. Эти же заболевания стали основной причиной госпитализации взрослого населения - 5,2\%о. Наиболее высокой больничная летальность была при внутримозговом и другом внутричерепном кровоизлиянии - 53,3\%, при субарахноидальном кровоизлиянии - 29,8\%, при инфаркте мозга - 23\%. На протяжении последних 5 лет отмечено снижение показателей смертности всего населения от цереброваскулярных болезней, особенно от инсультов.

Заключение. В результате проведенного медико-статистического анализа получена количественная характеристика размеров и динамики заболеваемости, летальности и смертности населения от цереброваскулярных болезней в целом по Московской области в 2014 г. Мониторинг на областном уровне позволит определить эффективность реализации разработанных мероприятий, направленных на снижение указанных показателей.Подөбпый анализ на уровне медицинского округа или муниципального образования позволит оценить “вклад» территории в размер явления и определить ее ранговое место.

Ключевые слова: цереброваскулярные болезни, инсульт, заболеваемость, больничная летальность, смертность. 
$\mathrm{M}$ едико-социальная значимость цереброваскулярных заболеваний обусловлена их влиянием на состояние здоровья и качество жизни населения, значительной распространенностью и высоким показателем смертности. В Российской Федерации смертность от инсульта остается одной из наиболее высоких в мире. Так, в нашей стране смертность населения от заболеваний сосудов головного мозга в 4 раза выше, чем в Канаде и США [1]. Єолоше 1 млн человек, проживающих в Российской Федерации, перенесли инсульт, ежегодно регистрируется около 100 тыс. случаев повторных инсультов [2]. Острые нарушения мозгового кровообращения являются одной из причин стойкой утраты трудоспособности населения во всем мире.

\section{Материал и методы}

В соответствии с Международной статистической классификацией болезней и проблем, связанных со здоровьем, 10-го пересмотра (МКБ-10) сосудистые заболевания головного мозга составляют группу цереброваскулярных болезней, в которую входят субарахноидальное кровоизлияние, внутримозговое и другое внутричерепное кровоизлияние, инфаркт мозга, инсульт, не уточненный как кровоизлияние или инфаркт, другие цереброваскулярные болезни и пр.

На основе данных ежегодных отчетных форм Федерального статистического наблюдения № 12 «Сведения о числе заболеваний, зарегистрированных у больных, проживающих в районе обслуживания лечебного учреждения» и № 14 «Сведения о деятельности стационара» были рассчитаны показатели общей заболеваемости (по обращаемости) взрослого населения Московской области, частоты госпитализации (госпитализированной заболеваемости) и показатели больничной летальности при цереброваскулярных болезнях. По материалам службы государственной статистики по Московской области проанализированы показатели смертности от болезней системы кровообращения, цереброваскулярных болезней и отдельных заболеваний, формирующих данную группу, среди всего населения.

\section{Результаты}

В 2014 г. в амбулаторно-поликлинические учреждения Московской области в связи с цереброваскулярными болезнями взрослым населением было сделано 209105 обращений. Общая заболеваемость (по обращаемости) цереброваскулярными болезнями, рассчитанная на
1000 соответствующего населения, составила 35,3 , в том числе отдельными заболеваниями: субарахноидальным кровоизлиянием - 0,1\%о, внутримозговым и другим внутричерепным кровоизлиянием - 0,2\%о, инфарктом мозга - $1,5 \%$, инсультом, не уточненным как кровоизлияние или инфаркт, - 0,6\%о, другими цереброваскулярными болезнями - 31,2\%о, из них церебральным атеросклерозом - 16,8\%. Следовательно, среди всех цереброваскулярных болезней ведущей причиной общей заболеваемости (по обращаемости) взрослого населения является группа заболеваний «другие цереброваскулярные болезни», включающая церебральный атеросклероз и другую хроническую патологию. Общая заболеваемость (по обращаемости) инсультом взрослого населения составляет $2,4 \%$.

При динамическом анализе за пятилетний период тенденция к снижению уровня общей заболеваемости выявлена при всей острой патологии (инсультах). В 2014 г. по сравнению с 2010 г. общая заболеваемость (по обращаемости) снизилась: при субарахноидальном кровоизлиянии - в 1,9, инсульте, не уточненном как кровоизлияние или инфаркт, - в 1,8, внутримозговом и другом внутричерепном кровоизлиянии - в 1,4, инфаркте мозга - в 1,1 раза. Показатели общей заболеваемости при хронической цереброваскулярной патологии в течение 5 лет изменялись волнообразно. Наиболее высокий уровень общей заболеваемости при церебральном атеросклерозе и других цереброваскулярных болезнях отмечен в 2013 г. $32,6 \%$ (17,9\%о в 2010 г.). В 2014 г. наблюдалось снижение заболеваемости, но минимальных значений анализируемого периода достигнуто не было.

В 2014 г. частота госпитализации взрослого населения (госпитализированная заболеваемость) при цереброваскулярных болезнях составила 9,4 на 1000 населения, в том числе при внутримозговом и другом внутричерепном кровоизлиянии - 0,5\%о, субарахноидальном кровоизлиянии - 0,07\%о, инфаркте мозга - 3,4\%о, инсультах, не уточненных как кровоизлияние или инфаркт, $0,1 \%$. Самая высокая частота госпитализации взрослого населения отмечена при других цереброваскулярных болезнях, состоящих из хронических заболеваний, - 5,2\%о. В абсолютных цифрах в 2014 г. в стационары Московской области по поводу цереброваскулярных болезней госпитализировано 55528 пациентов в возрасте 18 лет и старше (в том числе по поводу инсульта - 24 195), умерли 7200 (в том числе от инсульта - 6677), выписаны после перенесенного инсульта - 17 518. Среди взрослых пациентов, госпитализированных по 
Таблица 1. Больничная летальность взрослого населения Московской области от болезней системы кровообращения за период 2010-2014 гг.

\begin{tabular}{|c|c|c|c|c|c|c|}
\hline $\begin{array}{l}\text { цереброваскулярные болезни, } \\
\text { из них: }\end{array}$ & $160-169$ & 13,4 & 13,4 & 13,3 & 12,7 & 13,0 \\
\hline субарахноидальное кровоизлияние & 160 & 23,7 & 28,5 & 33,1 & 33,9 & 29,8 \\
\hline $\begin{array}{l}\text { внутримозговое и другое внутричерепное } \\
\text { кровоизлияние }\end{array}$ & 161,162 & 53,9 & 56,8 & 54,6 & 54,2 & 53,3 \\
\hline инфаркт мозга & 163 & 21,9 & 22,0 & 21,8 & 22,8 & 23,0 \\
\hline
\end{tabular}

Таблица 2. Динамика показателей смертности всего населения Московской области от болезней системы кровообращения (на 100 тыс.)

\begin{tabular}{|c|c|c|c|c|}
\hline Причины смерти & 2011 г. & 2012 г. & 2013 г. & 2014 г. \\
\hline Болезни системы кровообращения, в том числе: & 845,3 & 872,7 & 844,7 & 791,5 \\
\hline цереброваскулярные болезни, из них: & 227,3 & 231,7 & 220,8 & 201,0 \\
\hline инсульты & 176,7 & 173,7 & 164,5 & 153,6 \\
\hline
\end{tabular}

поводу болезней системы кровообращения, пациенты с цереброваскулярными болезнями составили $23,9 \%$, среди умерших в стационаре от болезней системы кровообращения - 43,9\%.

Важным показателем, характеризующим качество лечения больных, является больничная летальность. В результате медико-статистического анализа установлено, что в 2014 г. больничная летальность взрослого населения (18 лет и старше) в стационарах медицинских организаций Московской области от всех болезней системы кровообращения составила 7,1\%, от цереброваскулярных болезней - 13,0\%. При отдельных заболеваниях, входящих в число цереброваскулярных болезней, больничная летальность была высокой: при внутримозговом и другом внутричерепном кровоизлиянии - 53,3\%, субарахноидальном кровоизлиянии - $29,8 \%$, инфаркте мозга $-23 \%$.

Анализ динамики показателей больничной летальности за последние 5 лет показал отсутствие четкой тенденции к их снижению на протяжении всего периода наблюдения (табл. 1).

В 2014 г. доля цереброваскулярных болезней среди причин смертности всего населения от болезней системы кровообращения составила $25,4 \%$, населения трудоспособного возраста 16,9\%. Как видно из данных табл. 2, в 2012 г. отмечен рост показателей смертности от болезней системы кровообращения и цереброваскулярных болезней, в последующие годы произошло снижение показателей. Смертность от инсультов имела выраженную тенденцию к снижению c 2011 г.

\section{Заключение}

Несмотря на положительную динамику многих показателей, уровень заболеваемости цереброваскулярными болезнями, летальности и смертности остается очень высоким. Для их быстрейшего снижения со стороны органов и учреждений здравоохранения требуется безусловное выполнение всех мероприятий, намеченных государственной программой «Здравоохранение Подмосковья» и Приказом Минздрава Московской области от 6 февраля 2015 г. № 163 «Об утверждении плана мероприятий по проведению в 2015 году в Московской области Года борьбы с сердечно-сосудистыми заболеваниями». Особое внимание отводится дальнейшему расширению сети 
сосудистых центров и первичных сосудистых отделений, совершенствованию их работы и повышению качества лечения пациентов с острым коронарным синдромом и острым нарушением мозгового кровообращения, созданию службы медицинской реабилитации для подобных пациентов. По-прежнему высоко значение первичной и вторичной профилактики сердечно-сосудистых заболеваний, организации качественного диспансерного наблюдения больных, своевременного выявления и коррекции факторов риска, поддержания здорового образа жизни. Расчет статистических показателей на уровне области, медицинского округа и муниципального образования даст возможность оценить эффективность реализации мероприятий по снижению заболеваемости, летальности и смертности от цереброваскулярных болезней в Московской области. (е)

\section{Литература}

1.Бокерия ЛА, Гудкова РГ. Сердечно-сосудистая хирургия - 2010. Болезни и врожденные аномалии системы кровообращения. М. НЦССХ им. А.Н. Бакулева РАМН; 2011. 192 с.

2. Скворцова ВИ. Медицинская и социальная значимость проблемы инсульта. Качество жизни. Медицина. 2004;(4):2-6.

\section{References}

1. Bokeriya LA, Gudkova RG. Serdechno-sosudistaya khirurgiya - 2010. Bolezni i vrozhdennye anomalii sistemy krovoobrashcheniya [Cardiovascular surgery - 2010. Circulatory diseases and congenital abnormalities]. Moscow: NTsSSKh im. A.N. Bakuleva RAMN [Bakulev Sci- entific Center of Cardiovascular Surgery]; 2011. 192 p. (in Russian).

2. Skvortsova Vl. Meditsinskaya i sotsial'naya znachimost' problemy insul'ta [Medical and social significance of the stroke problem]. Kachestvo zhizni. Meditsina. 2004;(4):2-6 (in Russian).

\title{
Cerebrovascular morbidity, lethality and mortality in the Moscow Region in 2014
}

\author{
Gurov A.N. • Katuntseva N.A.
}

Background: Cerebrovascular disorders are major contributors into mortality of the population. Annually, more than 14000 subjects die of cardiovascular disorders in the Moscow Region, $50 \%$ of them when being in a hospital.

Aim: Informational support of the programs aimed at decreasing of populational morbidity, lethality and mortality from cerebrovascular disorders, including stroke, improvement of healthcare quality and finally maintenance of patients' health and quality of life.

Materials and methods: We calculated rates of mortality, in-hospital lethality, total (according to referrals) and hospital incidence of cerebrovascular disorders in the Moscow Region in 2014. The sources of information were report forms of the Federal statistical surveillance \#12 and \#14, as well as materials of the State Statistical Service of the Moscow Region, related to mortality of the population. Changes of the parameters during the last years were monitored.

Results: The leading cause of total morbidity (reg istered according to referrals) among the adult population of the Moscow Region is "other cerebrovascular disorders" category (ICD-10) that include cerebrovascular atherosclerosis and other chronic diseases (35.3 per 1000 of population). The same group of disorders was the main cause of hospitalization among adults (5.2\%o). The highest in-hospital lethality was registered for intracerebral and other intracranial hemorrhage (53.3\% of cases), for subarachnoid hemorrhage (29.8\%), and for cerebral infarction (23\%). During the last years, there was a decrease in population cerebrovascular mortality rates, especially mortality from strokes.

Conclusion: The medical and statistical analysis allowed quantification of amount and changes in populational cerebrovascular morbidity, lethality and mortality in the Moscow Region as a whole in 2014 Regional monitoring would allow for determination of the efficacy of implementation of the planned measures aimed at lowering of these parameters. Such analysis performed at the level of a medical district or at municipal level would make it possible to assess a "contribution" of a territory into the general problem and to determine its rank.

Key words: cerebrovascular disorders, stroke, incidence, in-hospital lethality, mortality.
Gurov Andrey Nikolaevich - MD, PhD, Professor, Head of Department of Science and Organization $\triangle$ 61/2-3 Shchepkina ul., Moscow, 129110, Russian Federation. Tel.: +7 (495) 6844587. E-mail:kafedraoz@mail.ru

Katuntseva Nina Aleksandrovna - PhD, Associate Professor, Head of Department of Public Health Problems and Regional Healthcare Programs
1 Moscow Regional Research and Clinical Institute (MONIKI); 61/2 Shchepkina ul., Moscow, 129110, Russian Federation 